\title{
Cuidado, comunidad y singularidad son lo sustancial para una salud mental post manicomial en tiempos pandémicos
}

\section{Care, community, and uniqueness are at the core of post- asylum mental health in pandemic times}

\author{
Agustín Barua Caffarena ${ }^{a}$
}

\begin{abstract}
Resumen
El tiempo pandemizado nos plantea tenazmente incertidumbres que angustian y a la vez posibilitan. Por largo tiempo en Paraguay viene siendo mayoritaria la postura de abordar las problemáticas del sufrimiento psíquico a través de lógicas de encierro. En este trabajo hacemos una introducción sobre la noción de desmanicomialización en tanto paradigma ético-político. Luego planteamos posibles problemas centrales de nuestra sociedad manicomializada.

Finalmente hacemos varias propuestas de cambio a diferentes niveles para una política de salud mental desmanicomial partiendo de la referencia consignada por el psiquiatra de la referencial reforma de Trieste (Italia), Franco Basaglia: La libertad es terapéutica.
\end{abstract}

Palabras clave: desmanicomialización, políticas públicas de salud mental, pandemia de COVID-19, Paraguay.

\begin{abstract}
The pandemic weather tenaciously presents us with uncertainties that distress and at the same time make possible. For a long time, in Paraguay, the position of addressing the problems of mental suffering through the logics of confinement has been the majority. In this work we make an introduction about the notion of demanicomialization as an ethical-political paradigm. Then we raise possible core problems of our madhouse society.

Finally, we make several proposals for change at different levels for a demanicomial mental health policy, starting from the reference recorded by the psychiatrist of the referential reform of Trieste (Italy), Franco Basaglia: Freedom is therapeutic.
\end{abstract}

Keywords: deinstitutionalization, mental health public policies, COVID-19 pandemic, Paraguay. a Universidad Nacional de
Pilar, Paraguay.

Correspondencia a:

utopiandoya@gmail.com

Recibido:

10 de octubre de 2020

Aceptado:

12 de noviembre de 2020

\section{(c) (7)}

Artículo publicado en acceso abierto bajo la Licencia Creative Commons.

Cita:

Barua Caffarena, A. (2020).

Cuidado, comunidad y singularidad son lo sustancial para una salud mental post manicomial en tiempos pandémicos . Kera Yvoty: reflexiones sobre la cuestión social, 5, 24-30. 


\section{La pandemia extiende el manicomio}

Si la libertad es terapéutica, ¿por qué encerramos? En el contexto de la pandemia de la enfermedad por Coronavirus (COVID-19) hemos visto emerger varios problemas vinculados a la salud mental y los múltiples efectos nocivos de las lógicas de encierro, promovidas por las instituciones que, paradójicamente, son las responsables de garantizar derechos. Programas institucionales que violentan a las personas, promoviendo su depósito y hacinamiento en los refugios, con una fuerte carga de maltratos como medida más efectiva para contener los contagios, o el aumento de las medidas represivas en el hospital psiquiátrico, sumada a los padecimientos de trabajadores de salud con escasa o nula contención en su salud mental. Pero la acción se reafirma y legitima también en los discursos oficiales gubernamentales, que encuentran resonancia ideal en los medios predispuestos a la confrontación y a la propagación del miedo. Así escuchamos hablar de una "guerra contra el virus", que promueve la desconfianza, la hostilidad y hasta el odio hacia las personas en contacto o en sospecha de contacto con el coronavirus.

La pandemia trajo estos colaterales, pero también sirvió para empezar a reconocer la salud mental como un tema relevante.

\section{La normalidad manicomial: la normalidad pre-pandemia}

Se habla mucho de una "nueva normalidad”. Pero en salud mental ¿cómo era la "normalidad" que teníamos antes?

Dos puntos la ilustran.

El primero. Por todos lados, la locura siempre entendida como algo insultante, avergonzante, descalificante: "Especial... Demente... Desvariá... Retrasado... Tilinga... Mongo... Personaje... Intensa".

El segundo. Recuerdo que cuando comenzamos a trabajar en salud mental en el marco de la estrategia de Atención Primaria de Salud (APS) en el Bañado Sur de Asunción, preguntamos qué servicios de salud mental ofrecía el Estado en el territorio. La respuesta fue "recetas de sedantes que te dan los médicos en Capellanes", y la camioneta de la policía de la comisaría para la que se hacía "vaquita para el combustible para que se lleven a la gente al Neuro".

O sea, la oferta sanitaria consistía en, por un lado, que la persona sólo es pensada químicamente por lo que lo único que se le ofertan son "pastillas" (reduccionismo biologicista) y, por otro lado, aislamiento y encierro.

Esta precariedad no se ha podido cambiar ni siquiera durante el Gobierno de Fernando Lugo (2008 - 2012). El esfuerzo de iniciar un trabajo sanitario sistemático, territorial - comunitario, participativo en salud con la estrategia de APS fue truncado por aquel golpe parlamentario. ${ }^{2}$ Ya sea por falta de coraje en su dirección o por no ser una prioridad de ese ministerio, la Política Nacional de Salud Mental generada para el decenio 2010 - 2020 pese a su enfoque crítico y de avanzada, nunca se puso en acción por lo que no se modificó prácticamente en nada la predominancia de un modelo centrado en lo hospitalario, en la psicofarmacología y en el encierro.

\section{Desmanicomialización como paradigma ético-político}

¿Qué entendemos como lo ético aquí? Poder preguntar y preguntarse. ¿ $\mathrm{Y}$ cómo entendemos lo político? El poner en juego lo sensible para poder construir lo común.

Franco Rotelli define al manicomio como el lugar cero del intercambio, como una forma desnuda de dominio; la tutela,

\footnotetext{
1 Se refiere al Policlínico Capellanes del Chaco del barrio Roberto L. Petit.

2 El 22 de junio del 2012 se realizó un juicio político exprés al en ese momento Presidente de la República Fernando Lugo Méndez, que resulto en su destitución. El poder económico abortó así, un proceso electo democráticamente que amenazaba, aunque tímidamente, el control total que este ha tenido por más de 65 años en Paraguay.
} 
la internación tienen esa única finalidad: privar de los intercambios, establecer relaciones de mera dependencia personal (2015).

Desmanicomialización es una palabra que fue acuñada dentro del proceso de transformación de los servicios de salud mental y psiquiatría en la provincia de Río Negro (Argentina) e implica, según Cohen y Natella (2013), la apertura de una red de servicios de salud mental en la comunidad, la participación protagónica de la sociedad y de la familia, el respeto de los derechos fundamentales como condición para el bienestar mental y la inclusión social como objetivo principal (2013). Esto sólo es posible a través de la sustitución de la institución manicomial (u hospital psiquiátrico).

En Paraguay hay referencias importantes en este proceso (Arestivo \& Sauá, 2018; Moreno, 2008). Esta palabra tan ardua de pronunciar fue traducida por educadores populares de Caaguazu como ejedesencuadrá. ${ }^{3}$

\section{Problemas centrales de nuestra sociedad manicomializada}

A partir de experiencias previas en diferentes organizaciones y movimientos paraguayos de salud mental y derechos humanos $^{4}$ propongo los siguientes problemas vinculados a lo manicomial en la sociedad nacional.

Permanece anudada la idea de peligrosidad con la de locura. Nos dice Roberto Tykanori (2016)

La relación entre sociedad y manicomio es básicamente una relación de protección de la sociedad contra el sufriente mental, realizada por el manicomio. En ese sentido, es una relación asimétrica, prácticamente unidireccional, en la que los pacientes son secuestrados y enviados a un manicomio para ser custodiados. (p. 194)

\footnotetext{
3 Jopara (combinación de castellano y guaraní), desencuadrate.

4 Foro Permanente de Salud Mental, Colectivo Ombligo de Ingrid, Colectivo clinitaria. Sección de Psiquiatría crítica (Sociedad Paraguaya de Psiquiatría), Asociación Latinoamericana de Medicina Social, Capítulo Paraguay (ALAMES), entre otros.
}

Al no problematizarse el prejuicio, se validan todo tipo de conductas represivas de pretensión sanitaria como la internación compulsiva abusiva, la hipermedicación o la terapia electro convulsiva (electroshock).

Se naturaliza la idea de que encerrar es cuidar, validando una concepción carcelaria del cuidado, conocida como custodialismo.

Al ser "traducidas" las narraciones, las subjetividades, las contextualidades de las personas a una exclusiva respuesta psicofarmacológica, se reduce a las personas a su dimensión química. Este es un rasgo de la biomedicalización de lo humano.

Se mantiene una separación maniquea: "cordura todo bien, locura todo mal" donde lo normal es leído desde un lugar superior, normativo y disciplinante. Para problematizar esto, ayuda la noción de normopatías introducida por Joyce McDougall (1978) resalta la imposibilidadde rebelarse cuando corresponde, el mandato de adecuación permanente (cortés, ubicada, productiva) y la imposibilidad de quebrarse.

Por otro lado, hay prácticas identificadas específicamente en las instituciones de salud y de salud mental que potencian lo manicomial:

- Consultas individuales de salud mental seriales, con pobre construcción vincular y capacidad de escucha, sin contexto de la persona.

- Abordaje psiquiátrico reducido al relevamiento de signos y síntomas psiquiátricos y a una actualización de la medicación.

- Inducción a la población al uso abusivo de psicofármacos.

- Centralización de la tarea de salud mental en profesionales psi.

- No trabajo de potenciación y de construcción de redes comunitarias de cuidado.

- No reconocimiento de la complejidadydelaparticularidad 
de cada persona al abordar los procesos.

\section{Cambio de perspectiva personal para una salud mental colectiva y comunitaria desde la desmanicomialización}

Compartimos

algunas sugerencias para pensar la práctica de la desmanicomialización desde lo vincular y lo intersubjetivo.

- Reconocer nuestros propios impensables, entendiendo lo impensable como lo que sólo podemos pensar de una manera.

- Conocer nuestro propio "lado monstruoso", o sea reflexionar a partir de nuestra vivencia al haber atravesado experiencias donde fuimos tratadas como personas "raras", "extravagantes".

- "Amar es reconocer la diferencia del otro" es lo que nos decía la filósofa Marcia Tiburi (2015), proponiendo colocar lo amoroso al servicio de la diferencia.

- Ir deconstruyendo los autoritarismos que atraviesan las prácticas tradicionales en psiquiatría y en salud mental.

- Devolver a las personas su condición singular, particular, yendo más allá de las etiquetas psiquiátricas universalistas.

- Franco Basaglia decía que no cerramos manicomios si no corremos riesgos (1976).

- Apuntar a una perspectiva de derechos para las personas en diversidad psíquica es la base. Sus derechos, iguales e inalienables, establecen las bases para la libertad, la justicia y la paz.

- Estructurar nuestros modos de acompañamiento, nuestras instituciones en salud mental desde la priorización de la libertad y de la autonomía.

- Ser puentes entre las personas y la vida comunitaria. Así, lo territorial puede aportar cotidianeidad, complejidad y proximidad a nuestra clínica.

- Que cada profesional psi genere su propia experiencia singular de trabajo a partir de celebrar su propia rareza.

- Entender que necesitamos algo de la llamada normalidad para cuidarnos, pero en demasía ésta nos lleva al terror y a la parálisis. Por otro lado, necesitamos algo de la llamada locura para tres verbos sublimemente humanos: para cambiar, para crear, para arriesgar, pero que la sola locura nos impide el cuidar.

\section{Cuidado, comunidad y singularidad: cambiando el modelo}

Proponemos 8 ejes para construir políticas de salud mental en Paraguay más allá de los encierros (físicos con las internaciones compulsivas, químicos con la sobremedicación, simbólicos con las etiquetas psiquiátricas).

1. Sustitución progresiva hasta su cierre de los hospitales psiquiátricos. Generar lógicas de internación para crisis en salud mental no segregativas, no estigmatizantes. Para ello, necesitamos generar experiencias de internación voluntaria: domiciliarias con apoyo de la red de APS, comunitarias en los centros comunitarios de salud mental, y hospitalarias en salas de internación de crisis en hospitales generales.

Potenciar la estrategia de APS. Esta tiene características íntimamente vinculadas a un modelo de servicios de salud mental no manicomial. Su cercanía territorial que no desarraiga y que piensa desde la cotidianeidad compleja de cada persona, su abordaje centrado 
en la salud vincular (y no sólo en lo individual), el promover la participación y el protagonismo de las comunidades para transformar sus realidades. No es de balde la coincidencia entre su lema ("Cerca de la gente") y lo que nos decían dos grandes maestros Rotelly y Saraceno (2015) "Salud mental es cercanía social”.

2. Generar una red de servicios comunitarios de salud mental. Para sustituir al encierro necesitamos ir a las comunidades, a conocer $y$ a respetar sus culturas locales, a potenciar sus redes locales de cuidados creando redes de servicios de salud mental comunitaria. Es facilitar y sostener que cada persona tenga derecho efectivo a trabajar y/o estudiar con dignidad (y no como limosna), a socializarse en libertad, y a residir en un lugar donde sea bienvenida en el que tenga soberanía sobre el lugar.

3. Crear un órgano de revisión contralor autónomo. Esta institución es imprescindible para velar por los derechos de las personas que, como última alternativa, sean internadas compulsivamente.

4. La misma requiere representantes de diferentes estamentos (como organizaciones de derechos humanos, de personas usuarias o ex usuarias) que puedan hacer contrapeso a la psiquiatría manicomial y a su hegemonía cultural.

5. Formación desmanicomial en las profesionales sanitarias. Es imprescindible incidir en la formación de grado y postgrado donde se desnaturalice lo manicomial, se promueva el trabajo interdisciplinario, se valoren lo integral en los abordajes y se incluya la perspectiva de salud mental comunitaria.

6. Cambiar el paradigma hegemónico en drogas químicas. En una sociedad como la paraguaya donde el poder económico y político del narcotráfico es enorme, nos toca repensar como debilitar este poder y un paso es la legalización de las drogas químicas poniendo fin al moralismo químico (la separación en "legales e ilegales").

7. Porotrolado, necesitamosampliar nuestra forma de trabajar con personas complicadas con drogas químicas, complementando al abstencionismo con la perspectiva de reducción de daños.

8. Des manicomialización de toda la sociedad. No bastan las múltiples alternativas institucionales que sustituyan al manicomio. ${ }^{5}$ El proceso de transformación requiere pensar participativamente como dejamos los hondos prejuicios sobre la diferencia psíquica que son las que demandan encierro a partir de asociar locura con peligrosidad y la cordura como un todo adecuado.

9. Hay cuestiones culturales claves en Paraguay que, en gran medida ya tienen los valores de esta nueva mirada (inclusión, cuidados, afectos, comunidad) y pueden apuntalarlos como la amistad, lo

\footnotetext{
5 De las cuales, algunos ejemplos son: Centro comunitario de Salud Mental, Servicio de Urgencias en Hospital General, Hospital de Día, Apartamentos asistidos, Cooperativas sociales, Grupos de ayuda mutua, Farmacoterapia, Psicoterapias, Hospital de Noche, Residencias para la ejecución de medidas de seguridad, Servicio de psiquiatría infanto adolescente en hospital general, Red de equipos de Atención Primaria de Salud, Agentes comunitarias.
} 
familiar y los cristianismos.

10. No puede haber ni salud ni salud mental, sin justicia y bienestar social para toda la gente.

Finalmente, se ha visto que tres claves políticas para lograr la sustitución de las instituciones totales (Goffman) son la construcción de movimientos sociales en la que sean protagonistas las voces de personas usuarias y ex usuarias de salud mental, la fuerza de grupos de profesionales psico con una perspectiva crítica, y lograr el apoyo político para este proceso.

\section{Posibles líneas de trabajo en procesos locales institucionales de desmanicomialización}

Se presentan los mismos solo algunas de las líneas posibles, a modo de ejemplo y para ilustrar formas ya existentes, pero esto se precisará en el momento de acercamiento del proceso.

Demás está decir que estas líneas de trabajo no son fijas ni estáticas, las mismas se van modificando a lo largo del proceso.

- Potenciar la red de equipos de salud de la familia (APS). Esta tiene características íntimamente vinculadas a un modelo de servicios de salud mental no manicomial. Su cercanía territorial que no desarraiga y que piensa desde la cotidianeidad compleja de cada persona, su abordaje centrado en la salud vincular ( $y$ no sólo en lo individual), el promover la participación y el protagonismo de las comunidades para transformar sus realidades. No es de balde la coincidencia entre su lema ("Cerca de la gente") y lo que nos decían dos grandes maestros "Salud mental es cercanía social".

- Construcción de organizaciones que luchen contra la discriminación por salud mental (diversidad psíquica) y favorezcan su inclusión mental con protagonismo de personas usuarias y ex usuarias de salud mental.

- Promover la capacidad de intervención en crisis de salud mental de todo el servicio del hospital (desfragmentar la separación mente - cuerpo y generar un abordaje respetuoso de la complejidad humana).

- Generar proyectos cooperativos donde se incluya laboralmente a las personas usuarias.

- Trabajar en coordinación con las universidades locales favoreciendo que se generen profesionales con una mirada no manicomial y que potencien el trabajo departamental.

- Promover las redes de cuidado de salud mental comunitaria en las vecindades.

- Generar condiciones para la internación domiciliaria y hospitalaria locales evitando el desarraigo y la estigmatización que significa la internación manicomial (de la cual, nunca se regresa pues la persona pierde la confiabilidad social).

\section{La libertad es terapéutica}

Ojalá en este tiempo en que sabemos lo que es no tener libertad, en que sabemos lo que es estar encerrados, en que no sabemos lo que va a pasar, podamos como sociedad aprovechar a apostar a que, en adelante, lo que defina si una práctica es terapéutica, deje de ser el miedo que tengamos de la otra persona, y pase a ser el cuidado, la comprensión y el derecho a la libertad como algo innegociable.

\section{Agradecimientos}

A Noelia Ferreira por la concienzuda revisión y a Ignacio Irrazábal Ferreira por su salvadora limonada. 


\section{Referencias}

Arestivo, C., Sauá, A. (2018). Del Manicomio a la Comunidad Terapéutica. Hacia una psiquiatría más participativa. Arandurã.

Basaglia, F. (1976). La institución negada. Informe de un hospital psiquiátrico. Barral.

Cohen, H., \& Natella, G. (2013). La desmanicomialización: Crónica de la reforma del Sistema de Salud Mental en Río Negro.

McDougall, J. (1978). Plea for a measure of abnormality. International University Press.
Moreno, M. (2008). Tavyrai renda. Cuentos para des-manicomializar. Servilibro.

Rotelli, F., \& \& Saraceno, B. (2015). Vivir sin manicomios: La experiencia de Trieste. Editorial Topia.

Tiburi, M. (2015). Como conversar com um fascista. Editora Record.

Tykanori, R. (2016). Autopoiese e reforma psiquiátrica. São Paulo: Hucitec.

\section{Sobre el Autor}

Agustín Barúa Caffarena

Médico. Especialista en Psiquiatría de Atención Primaria de Salud. Magister en Antropología social. Certificado en Prácticas colaborativas y dialógicas. Psicoterapeuta en Clínica placera. Investigador en la Universidad Nacional de Pilar. Integrante del Colectivo Noimbái. Miembro de la Asociación Latinoamericana de Medicina Social (ALAMES) - Paraguay. Miembro de la Sección de Psiquiatría crítica - Sociedad Paraguaya de Psiquiatría. Director de psicodrama. 